\title{
Foreword
}

\section{Roddrick Colvin}

In at least one of the alternate universes, the Minnowbrook conference of 1968 not only established social equity as a foundation and area of inquiry for public administration, but was also the launch of gender equity as a central goal of the field. Attendees would have made the case that half of the population had been overlooked in our profession, as a population for academic inquiry, and as a community for whom policy and program implementation had been ignored. However, in this universe, the emergence of gender and public administration is only now being given serious consideration via this volume, the Handbook on Gender and Public Administration (hereafter Handbook).

I believe this volume is about 50 years overdue. It is hard to imagine what the field of public administration would look like today if it had made a dramatic course correction at the first Minnowbrook. Of course, women had been active in the practice of public administration for many years before Minnowbrook and were active in scholarship as well. I'm sure at least some of the social equity conversations at Minnowbrook included gender, and specifically, the plight of women, but gender did not take a prominent role in the study or application of public administration at the conference. It would take another 25 years before systematic conversations about gender in public administration would begin to form.

The bulk of my early research focused on sexual orientation and public administration. Because of this focus, I had a close relationship with scholars interested in gender and public administration for a number of years. In fact, the first book review I ever published reviewed the second edition of Camilla Stivers (2002) groundbreaking work, Gender Images in Public Administration. In revisiting that review from 20 years ago, I found that much of the praise and criticism of the book withheld this test of time.

Stivers's (2002) work provided a theoretical framework to help us understand the lack of representation of women in public administration, and why feminist theory had not taken a stronger hold in the field. Her analysis of expertise, leadership, management and virtue remains insightful today.

My concern at the time had to do with the evolution of masculine associations or images. Short of my "alternate universe" theory, nothing about the origins of public administration suggest an alternative course. At the time, I wrote:

Although expertise and leadership and management might indeed be infused with masculine images and structured to the exclusion of women, public administration is not unique in this aspect. If expertise and leadership and management in public administration should have evolved with fewer "masculine" structures or images, then one has to also make a case for the differing evolution. This is not to suggest that the inquiry of gender in public administration is not worthwhile, but it is to suggest that a stronger explanation of public administration's uniqueness (if that is the case) is needed. (Colvin, 2003, p. 84) 
From this perspective, the development of the Handbook represents the efforts of the authors and editors to change the evolution of the field. The Handbook is a logical extension of Stivers's seminal work as it seeks to move gender from the sideline to the center of administrative theory and practice.

Although my research agenda had been closely aligned with gender, as a cisgender male, my interaction and upstanding has changed over time. My next important encounter with gender in public administration would occur about a decade after reviewing Stivers's book, while working at the City University of New York. During my tenure at the University, a group of colleagues realized the dearth of gender-related research and discussion on campus. To address this deficit, my colleagues started an organization that was primarily focused on women in public service. The idea was to promote research in the field on and by women as well as provide mentoring for those interested in careers in public administration. I remember being approached by these colleagues and asked if I would allow my students to leave class early so that they could attend an information session. I was honored to be asked and excited to do my part to contribute to their success. That evening - to my chagrin - I sent the female students to the information session and released the male students early from the class to do whatever they wanted. It hadn't occurred to me that the gender-based issues in public administration were not issues that only affected women, nor did it occur to me that men have an equal responsibility in working to create more equity in public administration. In other words, even as recently as ten years ago, I viewed gender disparities within our field as primarily the purview or interest of women in public administration.

When my colleagues found out that I had sent the men home, they gently but firmly explained the need to have everyone actively engaged in fighting gender bias in the field, especially in research and mentoring.

Of course, they were absolutely right, and their perspective informed my research at the time, which was focused on female police officers in Argentina. There were two dramatic changes in the way that I approached this topic. First, I decided to gather data from female police officers not only about the challenges they faced in the workplace as women in a male-dominated profession, but also about the advantages and unique knowledge, skills and abilities they brought to policing as women. Second, I expanded my research to capture the views of male police officers and their understanding of gender equity in the workplace. This included inquiring about individual and organizational efforts to redress and/or ameliorate inequities based on police organizations.

With the publication of this Handbook, we get a comprehensive review and analysis of gender in public administration. The volume covers the historical and theoretical roots, considers gender and the context of many of our core interests, including budgeting and personnel. It provides cases - unique contexts - in which gender equity is applied. For me, each of these sections addresses perennial issues of the past, but more importantly, new angles and aspects for the field of public administration. For example, in Part I, the historical and theoretical roots underpinning the study of gender in public administration are explored. These chapters seek to amplify and bring forward works and ideas that have sometimes been overlooked when originally proposed, especially the theoretical explorations of gender in public administration. Just as we have gaps in our literature in other areas, these chapters contemplate perspectives not given due consideration in other formats or venues or times. This section is also important because it promotes intersectionality and places gender within the context of other identities like race and sexual orientation. Chapters in the section move us beyond a binary conception 
of men and women in public administration to a more nuanced discussion about gender equity and gender identities in public administration.

Part II might be the most informative section for those of us who were classically trained in public administration. This section offers insightful analysis of the functions of public administration through the lens of gender. While some scholars in the past have tried to promote gender-focused examinations of core functions in the field, this book represents a more comprehensive analysis of gender and public administration. This is especially useful because it discusses gender using frameworks familiar to most, if not all, administrators.

Finally, Part III examines public administration in context and tries to help us understand how gender paradigms affect the delivery of public goods and services. Within this context, I'm especially excited to see the examination of gender in an international context, including the global South. Examining gender in this context, we develop better models for understanding gender dynamics outside of the framework of the United States and American public administration. This is important because it presents both challenges and opportunities for understanding what it means to achieve gender equity. It also brings to our attention the struggle for gender equality globally.

In summary, the three Parts of this book help us to "see" gender within public administration and understand the social constructs that frame it. Our ability to recognize gender in public administration and its subsequent effects in the field gives us the ability to directly challenge decades' old ideas and beliefs. At the end of the day, the field of public administration and societies are improved when gender disparities are eliminated.

This book provides us with the tools, understanding and perspective to dismantle gender inequities, and to make real an equitable and representative discipline - and we won't even need to imagine it in alternative universes.

\section{REFERENCES}

Colvin, R. A. (2003). Book Review: Stivers, Camilla. (2002). Gender Images in Public Administration: Legitimacy and the Administrative State 2nd edition. Thousand Oaks, CA: Sage, 184 pp. Review of Public Personnel Administration, 23(1), 83-6.

Stivers, C. (2002). Gender Images in Public Administration: Legitimacy and the Administrative State (2nd edn.). Thousand Oaks, CA: Sage. 